\title{
SCIENTIFIC REPORTS

\section{Clinical characteristics, risk factors, and surgical outcomes of secondary macular hole after vitrectomy}

\author{
Hyun Goo Kang ${ }^{1,2}$, Jae Yong Han ${ }^{1}$, Eun Young Choi ${ }^{1}$, Suk Ho Byeon ${ }^{2}$, Sung Soo Kim², \\ Hyoung Jun Koh' ${ }^{2}$, Sung Chul Lee ${ }^{2} \& \operatorname{Min} \mathrm{Kim} \mathbb{1}^{1,2^{*}}$
}

Secondary macular hole $(\mathrm{MH})$ formation after vitrectomy is rare and its risk factors and pathogenesis are not clearly understood. This retrospective study was conducted to identify the risk factors of this complication and assess outcomes at 2 tertiary centres. The primary outcomes were the clinical characteristics associated with development of secondary $\mathrm{MH}$, which included the primary diagnosis for initial vitrectomy, features on optical coherence tomography, and adjuvant surgical techniques used during the initial surgery. Secondary outcomes included the change in best-corrected visual acuity(BCVA), clinical factors associated with the need for re-operations for $\mathrm{MH}$ closure and prognostic factors for the visual outcomes. Thirty-eight eyes out of 6,354 cases (incidence $0.60 \%$ ) developed secondary $\mathrm{MH}$ after undergoing vitrectomy for various vitreoretinal disorders over an 11-year period, most frequently after initial surgery for retinal detachment(RD) ( 9 eyes) and secondary epiretinal membrane ( 6 eyes). The mean age was 57.1 years (range: $17.8-76.7$ ), and the mean follow-up was 51.1 months (range: 6.8 to 137.6). Prior to secondary MH formation, development of ERM was the most common OCT feature (19 eyes, 50\%), and no cases of cystoid macular oedema (CME) were observed. A greater proportion of eyes with secondary $\mathrm{MH}$ had long axial lengths $(32 \% \geq 26 \mathrm{~mm}$ vs $5 \%$ of eyes $\leq 22 \mathrm{~mm}$ ). MH closure surgery was performed in 36 eyes and closure was achieved in 34 (success rate $94 \%$, final BCVA 20/86), with $\geq 3$-line visual gain in 18 cases. $B C V A$ at $M H$ onset $(O R=0.056, P=0.036)$, $B C V A$ at post-MH surgery month $3(O R=52.671, P=0.011)$, and axial length $\geq 28 \mathrm{~mm}(O R=28.487$, $P=0.030)$ were associated with $\geq 3$-line visual loss; a history of macula-off $R D(O R=27.158, P=0.025)$ was associated with the need for multiple surgeries for $\mathrm{MH}$ closure. In conclusion, secondary MH occurs rarely but most commonly after vitrectomy for RD. Patients with axial length $\geq 28 \mathrm{~mm}$ and poor BCVA at 3 months post-operation may have limited visual prognosis; those with a history of macula-off RD may require multiple surgeries for hole closure.

Secondary full-thickness macular hole $(\mathrm{MH})$ formation after vitrectomy is a rare surgical complication, with an incidence reportedly between $0.24 \%$ and $1.9 \%^{1-3}$. Unfortunately, the factors contributing to the development of a postoperative secondary $\mathrm{MH}$ in the absence of intact vitreous are not well-understood, and pathogenic mechanisms other than those for idiopathic $\mathrm{MH}$ may be involved. An idiopathic $\mathrm{MH}$ is generally believed to be formed as a result of interactions between various forces on the fovea, mainly from anteroposterior and tangential traction by the vitreous ${ }^{4,5}$. Therapeutic surgical intervention thus attempts to relieve these tractional components through vitrectomy, with or without internal limiting membrane (ILM) peeling, with favourable outcomes ${ }^{6,7}$. However, for post-vitrectomized eyes, the thorough detachment of the vitreous from the posterior pole and its removal eliminates these crucial pathogenic elements.

Current literature describes cases of secondary $\mathrm{MH}$ after surgical repair of retinal detachments (RD) ${ }^{8}$, epiretinal membranes (ERM) $)^{2}$, vitreomacular traction syndrome (VMTS $)^{9}$, and myopic foveoschisis ${ }^{10}$. These studies also document a wide combination of adjuvant techniques used during the initial vitrectomy, such as ILM peeling, scleral buckling, and pneumatic tamponade ${ }^{11}$. Many of the aforementioned studies also report that the vitreous was already detached prior to the primary vitrectomy ${ }^{12}$. Suggestions for possible aetiologies for secondary

${ }^{1}$ Department of Ophthalmology, Institute of Vision Research, Gangnam Severance Hospital, Yonsei University College of Medicine, 06273, Eonjuro 211, Gangnam-gu, Seoul, Republic of Korea. ²Department of Ophthalmology, Institute of Vision Research, Severance Eye Hospital, Yonsei University College of Medicine, 03722, Yonsei-ro 50-1, Seodaemun-gu, Seoul, Republic of Korea. *email: minkim76@gmail.com 


\begin{tabular}{|l|l|}
\hline Sex, no. (\%) & $18(49)$ \\
\hline Male & $19(51)$ \\
\hline Female & $9(24)$ \\
\hline Hypertension, no. (\%) & $9(24)$ \\
\hline Diabetes mellitus, no. (\%) & $55.7 \pm 14.1(17.6-75.4)$ \\
\hline Age at primary vitrectomy, years, mean \pm SD (range) & $57.1 \pm 14.6(17.8-76.7)$ \\
\hline Age at onset of MH & $2.3(0.4-90.9)$ \\
\hline Median time to MH diagnosis after vitrectomy, months (range) & $1.2 \pm 0.5(1-3)$ \\
\hline Prior vitrectomy operations, no. (range) & \\
\hline BCVA, logMAR, mean \pm SD (Snellen) & $1.19 \pm 0.9(20 / 313)$ \\
\hline Prior to primary vitrectomy & $1.02 \pm 0.6(20 / 210)$ \\
\hline Onset of MH & $25.1 \pm 2.7(21.5-32.3)$ \\
\hline Axial length, mm, mean \pm SD (range) & $2(5)$ \\
\hline Short eye $(\leq 22 \mathrm{~mm})$, no. (\%) & $24(63)$ \\
\hline Average eye (22-26 mm), no. (\%) & $12(32)$ \\
\hline Long eye ( $\geq 26 \mathrm{~mm})$, no. (\%) & $6(16)$ \\
\hline Very long eye $(\geq 28 \mathrm{~mm})$, no. (\%) & $28(74)$ \\
\hline Pseudophakic status, no. (\%) & \multicolumn{2}{|l|}{} \\
\hline
\end{tabular}

Table 1. Baseline patient characteristics ( 37 patients, $\mathrm{n}=38$ eyes). BCVA = best-correct visual acuity; $\log \mathrm{MAR}=\log$ arithm of minimum angle of resolution; $\mathrm{MH}=$ macular hole; $\mathrm{SD}=$ standard deviation.

MH formation include foveal cystic degeneration, iatrogenic trauma, secondary ERM tangential contraction, and vitreoschisis ${ }^{8}$. However, the small sample sizes in these previous studies, wide diversity of clinical characteristics, and varied outcomes pose difficulties in identifying common risk factors for the development of secondary $\mathrm{MH}$.

In this present study, we analysed a relatively large number of cases to investigate the clinical spectrum of a secondary $\mathrm{MH}$ that develops after vitrectomy and assess the treatment outcomes. Additionally, we sought to identify the risk factors that contribute to the development of secondary $\mathrm{MH}$ and the requirement of multiple surgeries for $\mathrm{MH}$ closure, and determine the predictive factors for long-term visual prognosis.

\section{Results}

A total of 38 eyes from 37 patients were included in this study, identified from 6,354 cases of patients who underwent vitrectomy, with an incidence of $0.60 \%$. The baseline characteristics are summarized in Table 1 . Secondary $\mathrm{MH}$ was diagnosed after a median duration of 2.3 months after the initial primary vitrectomy. The mean age at MH onset was 57.1 years, although it ranged from 17.8 to 76.7 years, and the mean onset BCVA was 1.02 (Snellen 20/210). There was no apparent predilection for sex; however, a greater proportion of the diseased eyes had long axial lengths ( $5 \%$ of eyes $\leq 22 \mathrm{~mm}$ vs. $32 \% \geq 26 \mathrm{~mm}$ ). The mean total follow-up duration was 51.1 months (range: 6.8 to 137.6 months).

The primary diagnoses for the initial vitrectomy, co-existing ocular pathologies detected on multimodal imaging, and adjuvant techniques used can be found in Table 2. The most common primary diagnoses for the initial vitrectomy, when defined as the principal reason for initial surgical treatment, were rhegmatogenous RD ( 9 eyes, $24 \%$; 5 macula-off cases) and secondary ERM (6 eyes, 16\%). When combining cases of primary rhegmatogenous RD (9 eyes) with those undergoing silicone oil removal after successful repair of RD with silicone oil tamponade (oil-filled status, 5 eyes) and those having had a history of RD $(n=3)$, we found that altogether 17 cases $(45 \%)$ had some association with RD.

Review of the multimodal imaging data of all involved eyes, before the initial vitrectomy, revealed a wide variety of co-existing vitreomacular pathologies in addition to the primary diagnosis, such as ERM detected in 22 eyes (58\%), vitreous haemorrhage in 11 eyes (29\%), retinoschisis in 5 eyes (13\%), and lamellar holes in 4 eyes (11\%) (Table 2). An intact subfoveal inner segment/outer segment line was observed on the OCT of 16 eyes (73\%) pre-operatively and only 8 eyes (35\%) post-initial vitrectomy. The mean central macular thickness was measured at $215.8 \pm 173.1 \mu \mathrm{m}$ preoperatively and $113.4 \pm 61.8 \mu \mathrm{m}$ post-operatively.

Next, we have summarized the clinical features detected after secondary MH formation (post-initial primary vitrectomy), and the intraoperative factors and surgical outcomes for $\mathrm{MH}$ closure in Table 3. We detected ERM in 19 eyes (50\%): recurred ERM in 14 eyes and newly developed ERM in 5 . We observed that all 4 cases of idiopathic ERM exhibited recurrence following the initial primary vitrectomy. No cases of cystoid macular oedema (CME) were detected prior to secondary $\mathrm{MH}$ formation.

Surgery for $\mathrm{MH}$ closure was performed in 36 eyes; the intraoperative factors and treatment outcomes are summarized in Table 3 . In the 2 cases that did not receive surgery, the patients refused treatment due to other debilitating illnesses, and were, therefore, managed conservatively. Successful closure, as detected on OCT, was achieved in 34 eyes (94\%) after a mean 1.3 operations. In majority of the eyes, ILM peeling was attempted (32 eyes, 89\%); however, no ILM staining was observed in 3 eyes (8\%). Furthermore, ILM transplantation (3 eyes, $8 \%$ ) and heavy silicone oil injection (1 eye, $3 \%$ ) was performed in eyes requiring multiple operation for closure. Representative images from several cases can be seen in patients with idiopathic ERM (Fig. 1), macula-off RD (Fig. 2), macular telangiectasia (Fig. 3), and submacular haemorrhage (Fig. 4). 


\begin{tabular}{|c|c|}
\hline Primary diagnosis, no. (\%) & $38(100)$ \\
\hline Rhegmatogenous RD (5 macula-off) & $9(24)$ \\
\hline Secondary epiretinal membrane & $6(16)$ \\
\hline Vitreous haemorrhage (4 PDR, 1 PCV) & $5(13)$ \\
\hline Oil-filled status after RD surgery (4 macula-off) & $5(13)$ \\
\hline Idiopathic epiretinal membrane & $4(11)$ \\
\hline Lamellar hole & $3(8)$ \\
\hline Submacular haemorrhage (2 PCV, 1 RAM) & $3(8)$ \\
\hline Vitreomacular traction syndrome & $2(5)$ \\
\hline Optic disc pit-associated maculopathy & $1(3)$ \\
\hline \multicolumn{2}{|c|}{ Co-existing pathology and clinical features prior to initial vitrectomy, no. (\%) } \\
\hline Epiretinal membrane detected on OCT & $22(58)$ \\
\hline Vitreous attachment at fovea on OCT & $22(58)$ \\
\hline Vitreous haemorrhage & $11(29)$ \\
\hline PDR & $4(11)$ \\
\hline Breakthrough from SMH & $3(8)$ \\
\hline PCV & $2(5)$ \\
\hline Branch retinal vein occlusion & $1(3)$ \\
\hline RAM & $1(3)$ \\
\hline Retinoschisis & $5(13)$ \\
\hline Lamellar macular hole & $4(11)$ \\
\hline Past surgical history of macula-off RD & $3(8)$ \\
\hline Prior scleral encircling or buckling for RD & $3(8)$ \\
\hline Proliferative vitreoretinopathy & $3(8)$ \\
\hline Posterior uveitis & $2(5)$ \\
\hline Prior oil removal history after RD & $1(3)$ \\
\hline Serous neurosensory RD & $1(3)$ \\
\hline RAM & $1(3)$ \\
\hline \multicolumn{2}{|l|}{ Adjuvant techniques for primary vitrectomy, no. (\%) } \\
\hline ILM peeling & $20(44)$ \\
\hline Pneumatic tamponade $\left(\mathrm{SF}_{6}\right.$ or $\mathrm{C}_{3} \mathrm{~F}_{8}$ gas $)$ & $16(42)$ \\
\hline Silicone oil injection & $12(32)$ \\
\hline Scleral buckle/encircling & $5(13)$ \\
\hline Intravitreal anti-VEGF injection performed & $12(32)$ \\
\hline No. of injections, mean \pm SD (range) & $2.6 \pm 2.0(1-7)$ \\
\hline Intravitreal Ozurdex ${ }^{\circledR}$ injection performed & $3(8)$ \\
\hline No. of injections, mean \pm SD (range) & $1.7 \pm 1.2(1-3)$ \\
\hline
\end{tabular}

Table 2. Diagnoses, associated ocular pathologies, treatment factors, and imaging characteristics with regard to the primary initial vitrectomy. ILM = internal limiting membrane; OCT = optical coherence tomography; $\mathrm{PDR}=$ proliferative diabetic retinopathy; $\mathrm{RAM}=$ retinal arterial macroaneurysm; $\mathrm{RD}=$ retinal detachment; $\mathrm{SD}=$ standard deviation; $\mathrm{SMH}=$ submacular haemorrhage; $\mathrm{VEGF}=$ vascular endothelial growth factor.

Visual outcomes and clinical factors. The mean BCVA at the most recent follow-up was 0.77 (20/119), with the majority (24 eyes, 63.2\%) having improved at least 1 line (Table 3 ). A visual loss of greater than 3 lines was noted in 7 eyes (18\%). Multivariable analyses found that the preoperative BCVA (odds ratio $[\mathrm{OR}]=0.056$, $P=0.036)$, BCVA at postoperative month $3(\mathrm{OR}=52.671, P=0.030)$, and axial length $\geq 28 \mathrm{~mm}(\mathrm{OR}=28.487$, $P=0.030$ ) significantly influenced a 3 -line visual loss by the final follow-up (Table 4). The size of $\mathrm{MH}$ was not found to be a significant factor for visual outcome in our regression analysis $(\mathrm{OR}=1.000(0.997-1.002)$, $P=0.726)$.

With regard to clinical factors predictive of requirement of multiple surgeries for $\mathrm{MH}$ closure, multivariable regression analysis revealed that a history of macula-off $\mathrm{RD}(\mathrm{OR}=27.158, P=0.025)$ significantly affected the outcome of Table 4. Other factors, such as MH size on preoperative OCT $(\mathrm{OR}=1.004, P=0.202)$, presence of perioperative ERM $(\mathrm{OR}=0.231, P=0.230)$, and $\mathrm{BCVA}$ at the most recent follow-up $(\mathrm{OR}=1.847, P=0.586)$, were only significant in the univariate analyses.

\section{Discussion}

Secondary MH after vitrectomy occurs rarely, with an incidence of $0.60 \%$ in our 11 -year retrospective review. While both tangential and anteroposterior traction are thought to be central to the pathogenesis of idiopathic $\mathrm{MH}$, subsequent studies using OCT have demonstrated that a predominantly anteroposterior orientation of tractional forces play a more crucial role ${ }^{13}$. Postoperative $\mathrm{MH}$ in the setting of absent vitreous, and therefore, no anteroposterior traction, however, raise questions regarding the responsible pathophysiology and underlying 


\begin{tabular}{|c|c|}
\hline MH size on pre-operative OCT, $\mu$ m, mean \pm SD (range) & $543.9 \pm 324.1$ \\
\hline ERM on OCT (after the initial vitrectomy but prior to MH surgery), no. (\%) & $19(50)$ \\
\hline Newly formed after the initial primary vitrectomy & $5(13)$ \\
\hline Recurrence after the initial primary vitrectomy \& ERM removal & $14(37)$ \\
\hline Surgery performed for MH closure, no. (\%) & $36(95)$ \\
\hline \multicolumn{2}{|l|}{ Adjuvant techniques during vitrectomy, no. (\%) } \\
\hline ILM peeling & $29(81)$ \\
\hline ILM transplantation & $3(8)$ \\
\hline No ILM staining observed & $3(8)$ \\
\hline Silicone oil injection & $7(19)$ \\
\hline Heavy silicone oil injection & $1(3)$ \\
\hline \multicolumn{2}{|l|}{ Pneumatic tamponade } \\
\hline $\mathrm{C}_{3} \mathrm{~F}_{8}$ gas injection & $26(72)$ \\
\hline $\mathrm{SF}_{6}$ gas injection & $6(17)$ \\
\hline Autologous platelet concentrate injection & $9(25)$ \\
\hline Closure of MH achieved, no. (\%) & $34(94)$ \\
\hline No. of operations to $\mathrm{MH}$ closure, mean $\pm \mathrm{SD}$ (range) & $1.3 \pm 0.5(1-3)$ \\
\hline Multiple operations required, no. (\%) & $10(28)$ \\
\hline \multicolumn{2}{|l|}{ Visual outcomes in BCVA, $\log M A R$, mean \pm SD (Snellen) } \\
\hline At post-operation 3 months ( $38 / 38$ eyes) & $1.00 \pm 0.6(20 / 199)$ \\
\hline At post-operation 6 months ( $38 / 38$ eyes) & $0.86 \pm 0.6(20 / 144)$ \\
\hline At post-operation 12 months ( $30 / 38$ eyes) & $0.78 \pm 0.6(20 / 119)$ \\
\hline At post-operation 24 months (26/38 eyes) & $0.63 \pm 0.5(20 / 86)$ \\
\hline Overall BCVA by the most recent follow-up & $0.77 \pm 0.7(20 / 119)$ \\
\hline Mean BCVA change from MH onset to final visit, $\log M A R$, mean \pm SD & $-0.25 \pm 0.6$ \\
\hline Improved at least 3 lines, no. (\%) & $18(47)$ \\
\hline Decreased in 3 lines, no. (\%) & $7(18)$ \\
\hline Follow-up duration, months, mean $\pm \mathrm{SD}$ (range) & $51.1 \pm 39.1(6.8-137.6)$ \\
\hline
\end{tabular}

Table 3. Clinical features after secondary macular hole formation: intraoperative factors and surgical outcomes. $\mathrm{BCVA}=$ best-corrected visual acuity; $\mathrm{ERM}=$ epiretinal membrane; ILM = internal limiting membrane; $\log \mathrm{MAR}=$ logarithm of minimal angle of resolution; $\mathrm{MH}=$ macular hole; $\mathrm{OCT}=$ optical coherence tomography; $\mathrm{SD}=$ standard deviation.

mechanisms $s^{3,11}$. In the present study, we examined our own experiences with this surgical complication, describing both the clinical spectrum and treatment outcomes, and have identified possible factors predictive of long-term prognosis.

There are currently two main theoretical mechanisms proposed for the aetiology of a secondary MH formation: the tangential forces from the formation of an ERM and the development of $\mathrm{CME}^{3}$. However, in our series, we did not detect any cases of CME after the primary vitrectomy and prior to the diagnosis of secondary $\mathrm{MH}$. Instead, we noted a greater prevalence of ERM, as detected on the OCT images of 27 distinct eyes (71\%) overall, both before and after the initial primary vitrectomy. These findings are similar to those of a recent study by Khurana et al. ${ }^{14}$, in which no eyes from 14 cases were found to have postoperative CME, but all eyes (100\%) had ERM (Table 5). It is important to note that in our series, OCT imaging was not available during the immediate post-operative period and prior to secondary $\mathrm{MH}$ diagnosis for all the cases, either due to the difficulty in capturing OCT images, such as after pneumatic tamponade, or irregular follow-up visits from the patients. Additionally, fluorescein angiography was not regularly performed after vitrectomy. Therefore, it is difficult to conclusively state that CME was not a factor for secondary MH development. However, it is revealing that we additionally observed secondary $\mathrm{MH}$ formation even in eyes that had received intraoperative Ozurdex ${ }^{\circledR}$, which is a sustained-release intravitreal dexamethasone implant that, in theory, should drastically reduce ocular inflammation and CME.

Previous clinical observations have revealed that the presence of ERM may be involved in the late reopening of successfully treated $\mathrm{MH}^{15,16}$, suggesting that tractional forces from the ERM could be responsible. However, the risk of ERM formation can be reduced with ILM peeling manoeuvres to remove all residual cortical vitreous ${ }^{17}$. In our series, we noted that ILM peeling had been performed in 20 eyes during the initial primary vitrectomy and ERM recurrence was noted in 9 cases, which may have been because of incomplete ILM removal or an insufficiently broad area of peeling. However, there were several eyes in our series that did not develop postoperative ERM, and simply detecting the presence of a postoperative ERM may not prove causation, instead suggesting heterogeneity in the aetiology of this postoperative complication.

Another possible mechanism responsible for secondary $\mathrm{MH}$ may involve the iatrogenic traction created during the induction of posterior vitreous detachment, ERM removal, or ILM peeling manoeuvres. A recent study by Sawaguchi et al. ${ }^{9}$ described a fascinating case of an $\mathrm{MH}$ developing intraoperatively during vitrectomy for VMTS, imaged on intraoperative OCT. As a result, the authors performed ILM peeling and pneumatic tamponade. 

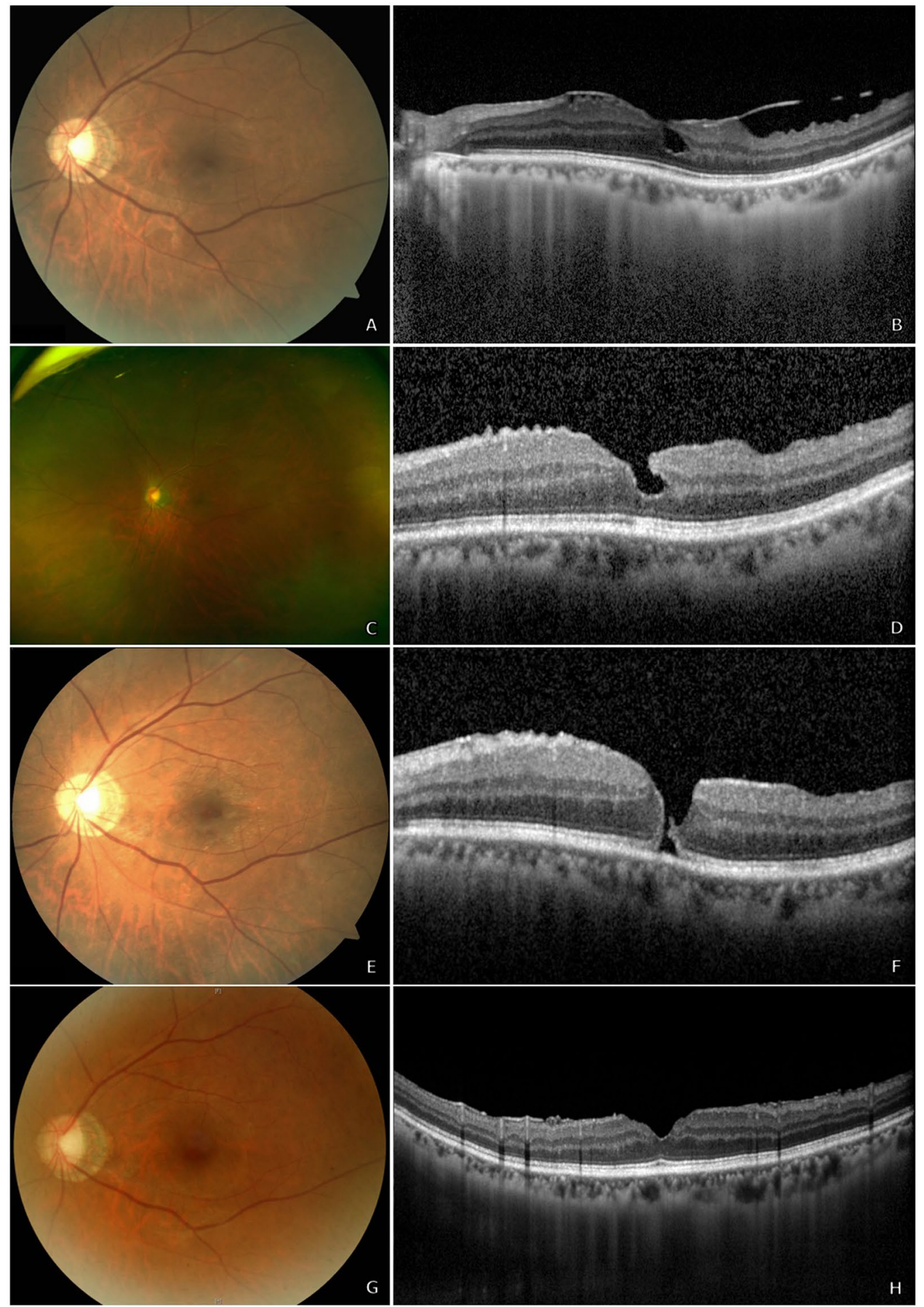

Figure 1. A 65-year-old woman underwent vitrectomy with internal limiting membrane (ILM) peeling for idiopathic epiretinal membrane (ERM) (A,B). Her best-corrected visual acuity (BCVA) was 20/133. Complete removal of ERM was noted on post-operative optical coherence tomography (OCT), although irregularity of the foveal depression remained (C,D). However, 1.7 months after the primary vitrectomy (BCVA 20/100), a secondary full-thickness macular hole $(\mathrm{MH})$ was detected on OCT with thin ERM and no evidence of cystoid macular oedema (E,F). She subsequently underwent vitrectomy with ILM peeling and pneumatic tamponade with C3F8 gas. The MH remained closed 2.5 years' post-operation, and her BCVA was 20/20 (G,H).

Additionally, previous studies consistently show a trend of $\mathrm{MH}$ formation after repair of RD involving the macula, but the underlying cause is yet to be fully understood ${ }^{11,18}$. This is similar to our own experience, where the majority of cases were associated with RD repair and multivariate analysis revealed that macula-off RD was the 

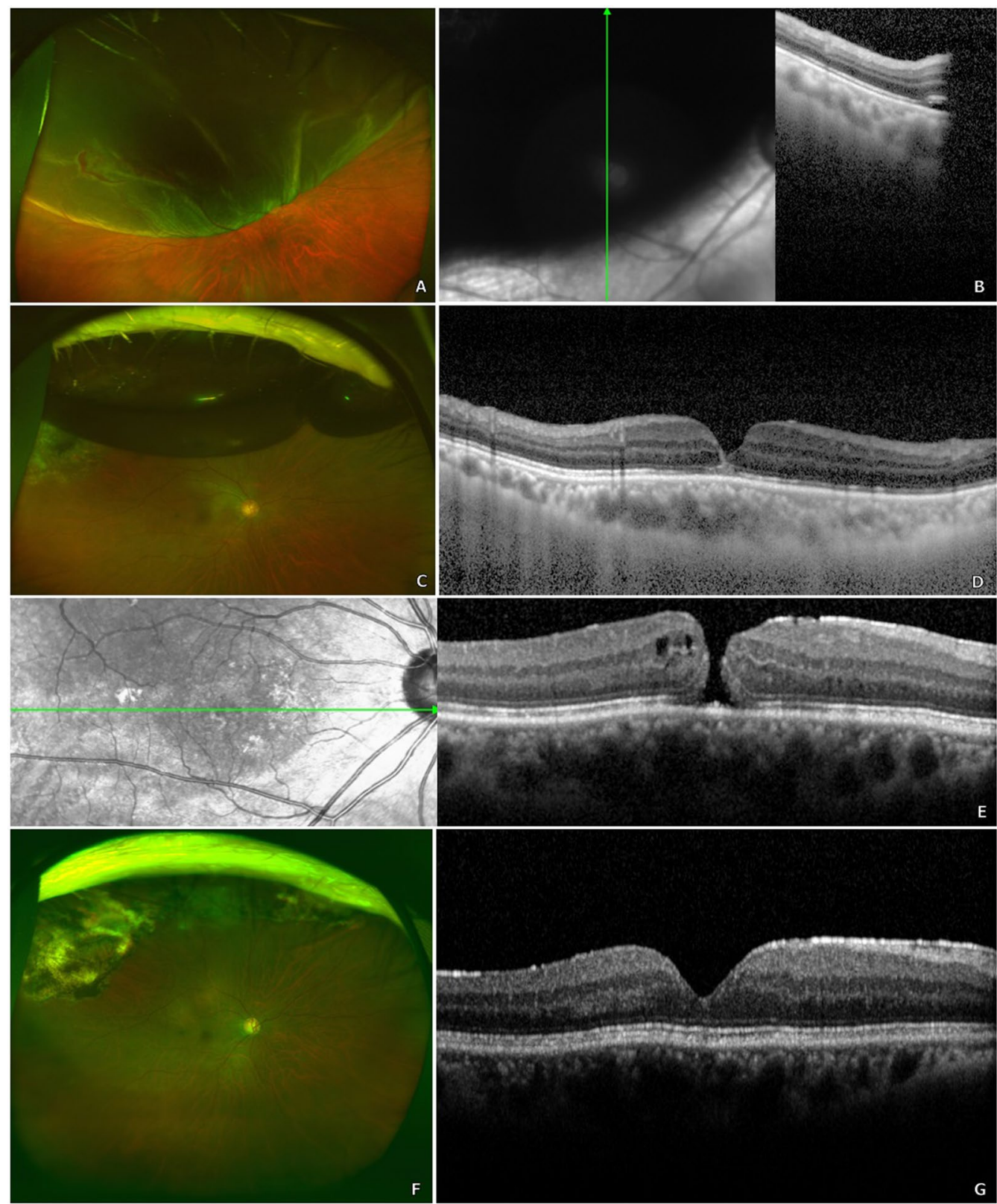

Figure 2. A man in his sixties underwent vitrectomy with pneumatic tamponade for macula-off retinal detachment in his right eye (A,B). His best-corrected visual acuity (BCVA) was 20/50. At postoperative week 5, the patient's retina was well-attached $(\mathbf{C})$; however, optical coherence tomography (OCT) revealed microscopic changes in foveal architecture and outer retinal layer discontinuity (D). Follow-up examination at postoperative week 8 (BCVA 20/67) revealed a secondary full-thickness macular hole (MH) with epiretinal membrane and without cystoid macular oedema (E). The patient underwent two additional vitrectomies with pneumatic tamponade and internal limiting membrane peeling for secondary $\mathrm{MH}$ closure. His most recent visit, at 3 years' post-operation, revealed a BCVA of 20/29 with a closed $\mathrm{MH}$, as observed on OCT (F,G).

most significant factor contributing to the need for multiple operations for $\mathrm{MH}$ closure. Altogether, these findings illustrate the complexity and possibly multifactorial nature of secondary $\mathrm{MH}$ formation. In the future, widespread use of intraoperative OCT may enable surgeons to consider the minute real-time changes in retinal architecture and further reduce complications.

Regarding the treatment outcomes, we found that the mean BCVA was improved at the final follow-up and more than 24 eyes (63\%) showed greater than 1-line visual gain. This is similar to the results of recent studies by Lee et al. ${ }^{2}$ and Khurana et al. ${ }^{14}$ which also found good visual recovery after surgery, with a high closure rate. We noted that poor long-term visual prognosis was most significantly associated with very long eyes (axial length $\geq 28 \mathrm{~mm}$ ), BCVA at onset, and poor BCVA at postoperative month 3. Association of secondary $\mathrm{MH}$ with high myopia has also been found in previous studies ${ }^{11}$, and poorer visual recovery in longer eyes may be explained by the observation that in highly myopic eyes, the macula tends to degenerate and the fovea tends to thin ${ }^{19}$. 

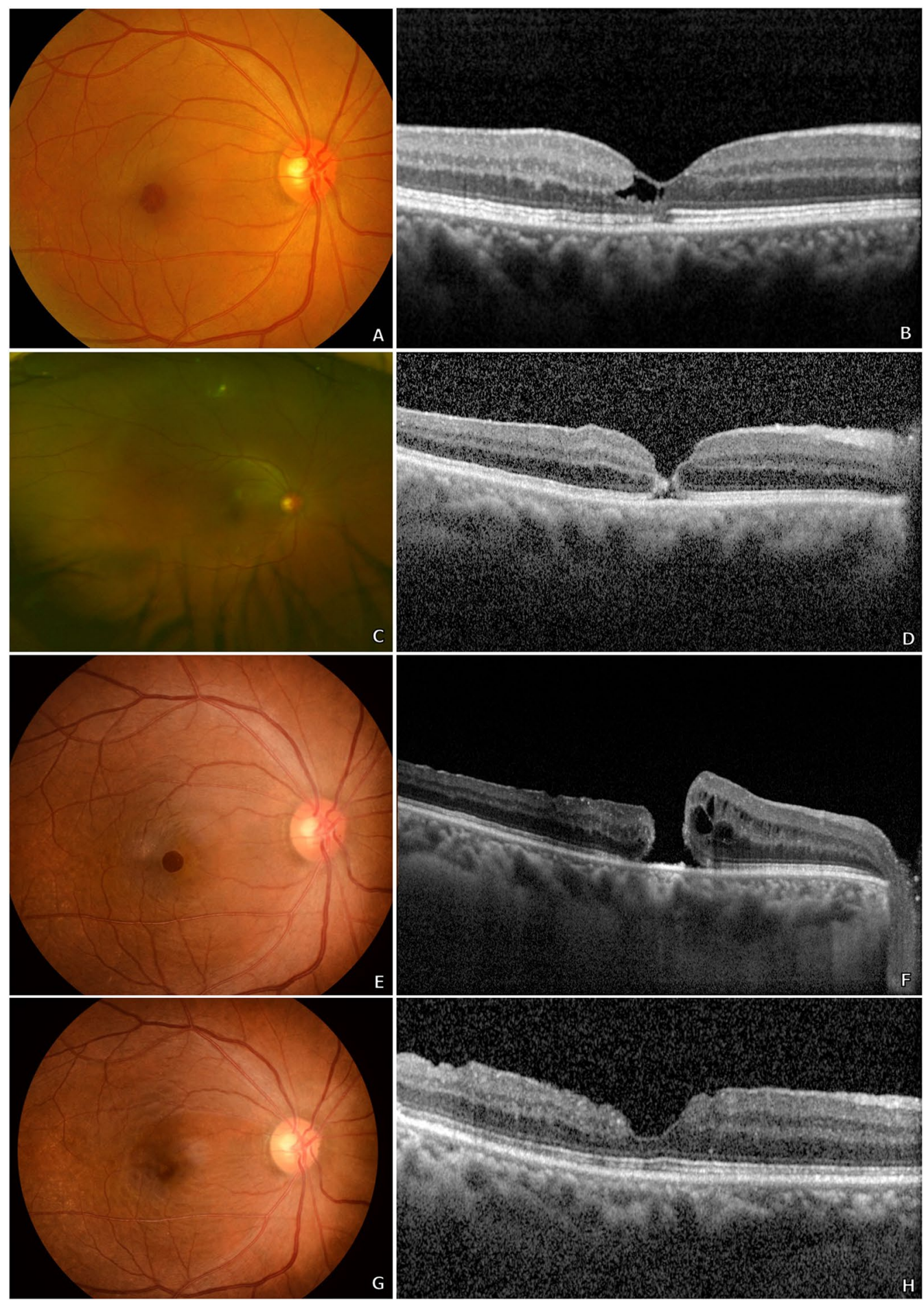

Figure 3. A 61-year-old woman underwent vitrectomy with wide internal limiting membrane (ILM) peeling for symptomatic lamellar hole due to type 2 macular telangiectasia (A,B). Her best-corrected visual acuity (BCVA) was 20/40. At postoperative day 5, imaging revealed a full-thickness macular hole (MH) with no evidence of cystoid macular oedema (C,D), and the patient's BCVA decreased to 20/100. Additional pneumatic retinopexy was performed twice subsequently but the size of the $\mathrm{MH}$ continued to increase (E,F). After two further vitrectomies with ILM peeling and injection of autologous platelet concentrate, $\mathrm{MH}$ closure was finally achieved. Three years' post-operation, the patient had a BCVA of 20/67 with a closed MH, as observed on optical coherence tomography $(\mathbf{G}, \mathbf{H})$.

In our case series, we observed that multiple operations were required in 10 cases (28\%), which is low compared with the results of a study by Medina et al. ${ }^{11}$ ( 7 out of 15 eyes, $47 \%$ ). However, this may be explained by the diversity of the primary diseases in our series, as the aforementioned study only included eyes with secondary 

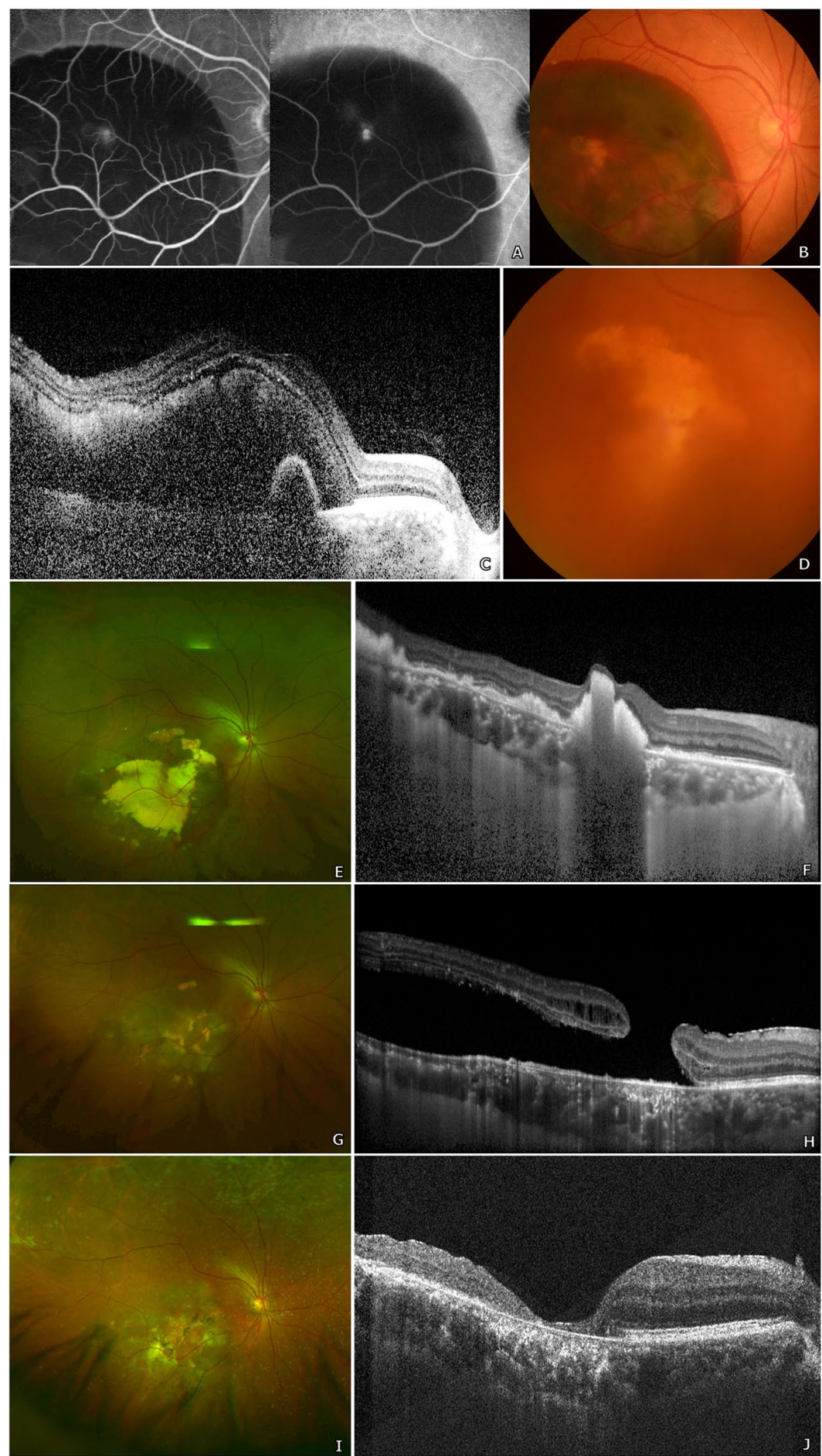

Figure 4. A woman in her early sixties with known submacular haemorrhage secondary to polypoidal choroidal vasculopathy, diagnosed based on typical multimodal imaging findings (A-C), underwent vitrectomy for breakthrough vitreous haemorrhage, which occurred after 2 intravitreal injections of anti-vascular endothelial growth factor (D). Her best-corrected visual acuity (BCVA) prior to initial vitrectomy was counting fingers. At post-operative month 2, multimodal imaging revealed a large subretinal hyperreflective material remaining under the fovea, although no definite macular hole $(\mathrm{MH})$ was yet to be found $(\mathbf{E}, \mathbf{F})$. However, 2 months later, after continual intravitreal anti- vascular endothelial growth factor injections, imaging studies revealed the formation a large secondary macular hole with localized retinal detachment $(\mathbf{G}, \mathbf{H})$ and her onset BCVA was 20/667. She subsequently underwent multiple vitrectomies for MH closure: internal limiting membrane peeling and pneumatic tamponade was performed initially. Additional surgery with injection of autologous platelet concentrate and silicone oil was implemented. Finally, once MH closure was evidenced on optical coherence tomography (OCT), silicone oil removal operation was performed. Her most recent examination, at 2 years after initial vitrectomy, revealed a well-closed MH on OCT (I,J) and a BCVA of 20/200. 


\begin{tabular}{|l|l|l|}
\hline \multicolumn{5}{|l|}{ Factors influencing a 3-line visual gain by the most recent follow-up } \\
\hline & OR (95\% CI) & P value \\
\hline BCVA, preoperative (prior to MH surgery) (logMAR) & $9.814(1.201-80.204)$ & $0.033^{*}$ \\
\hline BCVA, post-operation 3 months (logMAR) & $0.093(0.011-0.778)$ & $0.028^{*}$ \\
\hline Factors influencing a 3-line visual loss by the most recent follow-up \\
\hline \multicolumn{4}{|l|}{ OR (95\% CI) } & P value \\
\hline BCVA, preoperative (prior to MH surgery) (logMAR) & $0.056(0.004-0.825)$ & $0.036^{*}$ \\
\hline BCVA, post-operation 3 months (logMAR) & $52.671(2.436-1138.719)$ & $0.011^{*}$ \\
\hline Axial length $\geq 28$ mm & $28.487(1.380-587.960)$ & $0.030^{*}$ \\
\hline Factors influencing the need for multiple surgeries for MH closure & \\
\hline \multicolumn{4}{|l}{} & OR (95\% CI) & P value \\
\hline MH size on pre-operative OCT & $1.004(0.998-1.009)$ & 0.202 \\
\hline BCVA, most recent follow-up (logMAR) & $1.847(0.203-16.785)$ & 0.586 \\
\hline History of macula-off RD & $27.158(1.526-483.204)$ & $0.025^{*}$ \\
\hline Presence of perioperative epiretinal membrane & $0.231(0.021-2.520)$ & 0.230 \\
\hline
\end{tabular}

Table 4. Multivariable analyses of surgical and visual outcomes. BCVA = best-corrected visual acuity; $\mathrm{CI}=$ confidence interval; logMAR $=$ logarithm of minimal angle of resolution; $\mathrm{MH}=$ macular hole; $\mathrm{OR}=$ odds ratio; $\mathrm{RD}=$ retinal detachment; $* P<0.05$.

MH after RD repair. In cases requiring multiple operations, we used a maximal approach with a combination of adjuvant surgical manoeuvres such as ILM transplantation and autologous platelet injection for physiologic material to close the $\mathrm{MH}$, longer and more substantial mechanical pressure with injection of silicone oil and heavy silicone oil, and relieving of traction by thorough ILM peeling. Utilizing such methods, we successfully achieved $\mathrm{MH}$ closure in 34 eyes (94\%). Our findings suggest that, to improve the success rate of a single operation, greater caution may be required for eyes with a larger MH size, presence of perioperative ERM, and history of macula-off $\mathrm{RD}$, although only the last clinical factor was significant in multivariate analysis.

Although, to our knowledge, the current series is the largest describing secondary $\mathrm{MH}$ formation, it has several limitations due to its retrospective design with variable follow-up and without appropriate controls. The study population was limited to Asian patients in a tertiary university hospital setting. Finally, irregular patient follow-up and lack of immediate post-operative OCT may have led to delays in MH diagnosis. However, the strengths of this study include a large number of patients with a mean follow-up duration longer than 51 months, and treatment of all the patients at tertiary referral-based centres by experienced surgeons.

In summary, we found that secondary $\mathrm{MH}$ occurs rarely after vitrectomy, and the most commonly associated diagnosis was rhegmatogenous RD. Secondary ERM were noted in majority of the cases, suggesting that tangential forces may be the most important cause of this surgical complication. Although we observed that secondary $\mathrm{MH}$ can be successfully treated in most cases, patients with a history of macula-off RD may require multiple surgeries for hole closure, and those with very long eyes and poor BCVA at 3 months post-operation may have limited visual prognosis.

\section{Methods}

This retrospective study was conducted at two tertiary referral-based hospitals, Severance Hospital and Gangnam Severance Hospital, affiliated with Yonsei University College of Medicine. Consecutive patients who underwent vitrectomy from January 2006 to December 2016 were examined, and cases that developed a postoperative secondary MH were identified for inclusion. Institutional Review Board (Severance Hospital \& Gangnam Severance Hospital, Yonsei University Health System) approval was obtained, and informed patient consent was acquired. The study adhered to the tenets of the Declaration of Helsinki.

We reviewed the complete electronic medical records and multimodal imaging data of the identified cases. Multimodal imaging data, when available, included data from fundus photography, ultra-wide field scanning laser ophthalmoscopy (Optomap ${ }^{\circledR}$; Optos PLC, Dunfermline, UK), fluorescein and indocyanine-green angiography using a confocal scanning system (HRA-2; Heidelberg Engineering Inc., Heidelberg, Germany), and optical coherence tomography (OCT) (Heidelberg Spectralis from Heidelberg Engineering Inc., Heidelberg, Germany; or Cirrus HD-OCT from Carl Zeiss Meditec, Inc., Dublin, CA, USA).

Basic demographic parameters, including age, sex, follow-up duration, and medical histories, were obtained. The primary diagnosis for vitrectomy prior to secondary $\mathrm{MH}$ formation was determined through examination of both electronic charts and imaging data. Patients who had undergone initial surgery for MH were excluded. Macular holes were defined as full-thickness defects of the neurosensory retina at the foveal centre as detected on OCT.

Additional macular pathologies (such as the presence of ERM, retinal/submacular haemorrhages, age-related macular degeneration, retino/foveoschisis, foveal cystic changes, etc.) and vitreoretinal pathologies (proliferative diabetic retinopathies, retinal artery/vein occlusions, VMTS, posterior vitreous detachment, vitreous haemorrhage, etc.) both before and after the primary vitrectomy, as well as the history of surgical interventions (scleral encircling/buckling, intravitreal injections, pneumatic retinopexy, laser photocoagulation, cataract surgery, etc.) were documented. 


\begin{tabular}{|c|c|c|c|c|c|c|c|c|c|}
\hline $\begin{array}{l}\text { Authors, } \\
\text { Journal (Year) }\end{array}$ & $\begin{array}{l}\text { Secondary } \\
\text { MH after } \\
\text { PPV, Eyes } \\
\text { (Incidence) }\end{array}$ & $\begin{array}{l}\text { Mean Age, } \\
\text { Years } \pm \text { SD } \\
\text { (Range) }\end{array}$ & $\begin{array}{l}\text { Most Common } \\
\text { Diagnosis, } \\
\text { Eyes }(\%)\end{array}$ & $\begin{array}{l}\text { Mean Interval } \\
\text { Between Primary } \\
\text { PPV and MH } \\
\text { Diagnosis, Month } \\
\text { (Range) }\end{array}$ & $\begin{array}{l}\text { ERM/CME } \\
\text { Detected } \\
\text { Prior to MH } \\
\text { Diagnosis, } \\
\text { Eyes (\%) }\end{array}$ & $\begin{array}{l}\text { High } \\
\text { Myopia, } \\
\text { Eyes (\%) }\end{array}$ & $\begin{array}{l}\text { MH Surgical } \\
\text { Outcomes: } \\
\text { Successful Closure } \\
\text { Rate/Rate of } \\
\text { Multiple Operations }\end{array}$ & $\begin{array}{l}\text { Final Visual } \\
\text { Outcome, } \\
\text { Snellen's VA } \\
\text { (range): } \\
\text { Change in VA }\end{array}$ & $\begin{array}{l}\text { Study Conclusions and } \\
\text { Key Findings }\end{array}$ \\
\hline $\begin{array}{l}\text { Lee } \text { et al. }{ }^{2}, \\
\text { Retina }(2010)\end{array}$ & $\begin{array}{l}10(0.2 \% \\
\text { over } 5.3 \\
\text { years })\end{array}$ & $\begin{array}{l}56 \pm 16 \\
(27-78)\end{array}$ & $\begin{array}{l}\text { RD 5 (50\%); } \\
\text { VH due to } \\
\text { PDR 4 (40\%); } \\
\text { Idio-pathic } \\
\text { ERM } 1(10 \%)\end{array}$ & $\begin{array}{l}26 \\
(0.6-168)\end{array}$ & $\begin{array}{l}\text { ERM } 4(40 \%) / \\
\text { CME } 1(10 \%)\end{array}$ & $3(30 \%)$ & $\begin{array}{l}9(90 \%) \text { closed } / 0 \\
\text { multiple ops }\end{array}$ & $\begin{array}{l}20 / 460(20 / 21 \\
\text { to counting } \\
\text { fingers }): 2 \text {-line } \\
\text { decrease, } \\
2 \text { eyes }(20 \%)\end{array}$ & $\begin{array}{l}\text { Relatively favourable } \\
\text { outcomes, final VA } \\
\text { dependent on underlying } \\
\text { ocular pathology. }\end{array}$ \\
\hline $\begin{array}{l}\text { Garcia-Arumi } \\
\text { et al. }^{18}, \text { Retina } \\
(2011)\end{array}$ & $\begin{array}{l}14(0.6 \% \\
\text { after RD } \\
\text { repair over } \\
13 \text { years })\end{array}$ & $\begin{array}{l}52 \\
(29-70)\end{array}$ & $\begin{array}{l}\text { Macula-off RD } \\
14(100 \%)\end{array}$ & $\begin{array}{l}11 \\
(0.8-78)\end{array}$ & $\begin{array}{l}\text { ERM } 45 \% \\
\text { overall/CME } \\
\text { no data }\end{array}$ & $3(21 \%)$ & $\begin{array}{l}14(100 \%) \text { closed } / 0 \\
\text { multiple ops }\end{array}$ & $\begin{array}{l}20 / 100 \\
(20 / 28- \\
20 / 400): \\
14(100 \%) \\
\text { improved } \\
\text { compared to } \\
\text { pre-op }\end{array}$ & $\begin{array}{l}\text { Favourable MH closure } \\
\text { rate, though limited } \\
\text { functional VA outcome. }\end{array}$ \\
\hline $\begin{array}{l}\text { Schlenker } \\
\text { et al. } .^{3}, \text { Can J } \\
\text { Ophthalmol } \\
(2012)\end{array}$ & $\begin{array}{l}9(0.9 \% \\
\text { after RD } \\
\text { repair over } \\
4.5 \text { years })\end{array}$ & $\begin{array}{l}49 \\
(9-73)\end{array}$ & $\begin{array}{l}\text { RD } 9(100 \%): \\
\text { macula-off } \\
8(89 \%), \text { re- } \\
\text { current } 5(56 \%)\end{array}$ & $\begin{array}{l}\text { median } 4 \\
(0.07-22)\end{array}$ & $\begin{array}{l}\text { ERM } 2(22 \%) / \\
\text { CME no data }\end{array}$ & $1(11 \%)$ & $\begin{array}{l}8(89 \%) \text { closed/2 } \\
(22 \%) \text { multiple ops }\end{array}$ & $\begin{array}{l}20 / 200(20 / 50 \\
\text { to counting } \\
\text { fingers): } 1 \text {-line } \\
\text { increase, } \\
5 \text { eyes }(56 \%)\end{array}$ & $\begin{array}{l}\text { CME may play a } \\
\text { prominent role. } \\
\text { Favourable } \mathrm{MH} \text { closure } \\
\text { rates, though visual } \\
\text { prognosis remains } \\
\text { guarded. }\end{array}$ \\
\hline $\begin{array}{l}\text { Fabian et al. }{ }^{8} \text {, } \\
\text { Retina (2012) }\end{array}$ & $\begin{array}{l}7(1.1 \% \\
\text { after RD } \\
\text { repair over } \\
4.5 \text { years })\end{array}$ & $\begin{array}{l}60 \pm 10 \\
(50-79)\end{array}$ & $\begin{array}{l}\text { RD } 7(100 \%): \\
\text { macula-off } 3 \\
(30 \%)\end{array}$ & $\begin{array}{l}20 \\
(1-48)\end{array}$ & $\begin{array}{l}\text { ERM } 2(29 \%) / \\
\text { CME none }\end{array}$ & (no data) & $\begin{array}{l}5 \text { out of } 7(71 \%) \\
\text { closed/1 }(14 \%) \\
\text { multiple ops }\end{array}$ & $\begin{array}{l}\text { 20/74 (20/25- } \\
20 / 480): \\
3(43 \%) \\
\text { improved } \\
\text { compared to } \\
\text { pre-op }\end{array}$ & $\begin{array}{l}\text { Suggests iatrogenic } \\
\text { trauma during PPV, } \\
\text { vitreoschisis, ILM } \\
\text { traction may cause } \\
\text { secondary MH. }\end{array}$ \\
\hline $\begin{array}{l}\text { Gao et } \\
\text { al. } .^{10}, \text { Am J } \\
\text { Ophthalmol } \\
\text { (2013) }\end{array}$ & $\begin{array}{l}8(19 \% \text { after } \\
\text { foveoschisis } \\
\text { repair over } \\
10 \text { years })\end{array}$ & $\begin{array}{l}69 \pm 13 \\
(51-83)\end{array}$ & $\begin{array}{l}\text { Myopic } \\
\text { foveoschisis } \\
(100 \%)\end{array}$ & $\begin{array}{l}1.6 \\
(1-3)\end{array}$ & (no data) & $\begin{array}{l}\text { Myopia } \\
>6 \mathrm{D} \text { or AXL } \\
>26.5 \mathrm{~mm}: 8 \\
(100 \%)\end{array}$ & (no data) & (no data) & $\begin{array}{l}\text { Chorioretinal atrophy/ } \\
\text { posterior staphyloma } \\
\text { not significant. Loss of } \\
\text { IS/OS line integrity risk } \\
\text { factor for secondary MH } \\
\text { development. }\end{array}$ \\
\hline $\begin{array}{l}\text { Medina et al. }{ }^{11}, \\
\text { Retina (2017) }\end{array}$ & $\begin{array}{l}15 \text { (no } \\
\text { data on } \\
\text { incidence) }\end{array}$ & $\begin{array}{l}64 \\
(50-86)\end{array}$ & $\begin{array}{l}\text { RD } 15(100 \%): \\
\text { macula-off } \\
9(60 \%), \text { re- } \\
\text { current } 9(60 \%)\end{array}$ & $\begin{array}{l}4 \\
(1-13)\end{array}$ & $\begin{array}{l}\text { ERM } 11 \\
(73 \%) / C M E \\
\text { none }\end{array}$ & $\begin{array}{l}\text { Myopia } \\
>6 \mathrm{D} \text { or AXL } \\
>26.5 \mathrm{~mm}: \\
5 \text { out of } 9 \\
(56 \%)\end{array}$ & $\begin{array}{l}11(73 \%) \text { closed/7 } \\
(47 \%) \text { multiple ops }\end{array}$ & $\begin{array}{l}20 / 267(20 / 60 \\
\text { to hand } \\
\text { motions): } \\
2 \text {-line } \\
\text { increase, } 8 \\
\text { eyes }(53 \%)\end{array}$ & $\begin{array}{l}\frac{\text { Secondary MH may }}{\text { be associated with }} \\
\underline{\text { ERM, macula-off RD, }} \\
\text { recurrent RD, and high } \\
\text { myopia. Limited visual } \\
\text { improvement even after } \\
\text { MH closure. }\end{array}$ \\
\hline $\begin{array}{l}\text { Khurana et } \\
\text { al. }{ }^{14} \\
\text { Retina (2017) }\end{array}$ & $\begin{array}{l}14 \text { (no } \\
\text { data on } \\
\text { incidence) }\end{array}$ & $\begin{array}{l}61 \\
(43-71)\end{array}$ & $\begin{array}{l}\text { RD 14 (100\%): } \\
\text { macula-off RD } \\
6(43 \%)\end{array}$ & $\begin{array}{l}\text { median } 15 \\
(1-78)\end{array}$ & $\begin{array}{l}\text { ERM } 14 \\
(100 \%) / C M E \\
\text { none }\end{array}$ & (no data) & $\begin{array}{l}12 \text { out of } 12(100 \%) \\
\text { closed/0 multiple ops }\end{array}$ & $\begin{array}{l}20 / 25(20 / 20 \\
\text { to counting } \\
\text { fingers): } \\
13(93 \%) \\
\text { improved } \\
\text { compared to } \\
\text { pre-op }\end{array}$ & $\begin{array}{l}\text { ERM may play a role in } \\
\text { the pathogenesis of } M H .\end{array}$ \\
\hline $\begin{array}{l}\text { Kang et al., } \\
\text { Present Study }\end{array}$ & $\begin{array}{l}38(0.6 \% \\
\text { over } 10 \\
\text { years })\end{array}$ & $\begin{array}{l}57 \pm 15 \\
(18-77)\end{array}$ & $\begin{array}{l}\text { RD } 9(23.7 \%) \\
\text { with } 5 \text { macula- } \\
\text { off; secondary } \\
\text { ERM } 6(15.8 \%)\end{array}$ & $\begin{array}{l}\text { median } 2.3 \\
(0.04-91)\end{array}$ & $\begin{array}{l}\text { ERM } 19 \\
(50 \%) / C M E \\
\text { none }\end{array}$ & $\begin{array}{l}\text { AXL } \\
>28 \mathrm{~mm}: 6 \\
(15.8 \%)\end{array}$ & $\begin{array}{l}34 \text { out of } 36(94 \%) / 10 \\
(28 \%) \text { multiple ops }\end{array}$ & $\begin{array}{l}20 / 86(20 / 25 \\
\text { to counting } \\
\text { fingers): } 3 \text {-line } \\
\text { increase, } 18 \\
(47 \%)\end{array}$ & $\begin{array}{l}\text { Occurs most commonly } \\
\text { after RD repair, } \\
\text { associated with ERM. } \\
\text { AXL } \geq 28 \mathrm{~mm} \text { and poor } \\
\text { BCVA at } 3 \text { months } \\
\text { associated with limited } \\
\text { outcome. History of } \\
\text { macula-off RD risk factor } \\
\text { for multiple surgeries for } \\
\text { MH closure. }\end{array}$ \\
\hline
\end{tabular}

Table 5. Literature review — secondary macular hole formation after vitrectomy in different studies. $\mathrm{AXL}=$ axial length; $\mathrm{BCVA}=$ best-corrected visual acuity; $\mathrm{CME}=$ cystoid macular oedema; $\mathrm{ERM}=$ epiretinal membrane; ILM = internal limiting membrane; IS/OS = inner segment/outer segment; $\mathrm{MH}=$ macular hole; $\mathrm{RD}=$ retinal detachment; $\mathrm{PDR}=$ proliferative diabetic retinopathy; $\mathrm{PPV}=$ pars plana vitrectomy; $\mathrm{SD}=$ standard deviation; $\mathrm{VA}=$ visual acuity; $\mathrm{VH}=$ vitreous haemorrhage.

All vitrectomies were performed using either a 23- or 25-gauge system (Constellation ${ }^{\circledR}$ Vision System; Alcon Laboratories, Fort Worth, TX, USA) depending on the surgeon's preference. Adjuvant techniques that were utilized during either the primary vitrectomy or subsequent vitrectomies for MH closure were noted, such as ILM peeling and/or transplantation, laser photocoagulation, pneumatic tamponade, silicone oil injection, intravitreal injections, and autologous platelet injection. The number of operations prior to secondary $\mathrm{MH}$ formation and the number of subsequently required surgeries for $\mathrm{MH}$ closure were noted; $\mathrm{MH}$ was considered successfully closed when continuous inner retinal layers without intraretinal cysts were observed on OCT.

The best-corrected visual acuity (BCVA) was recorded by Snellen visual acuity and converted to logarithm of minimal angle of resolution (logMAR) scale for evaluation. We noted all available BCVA data at the following time intervals: prior to primary vitrectomy, onset of $\mathrm{MH}$, and post- $\mathrm{MH}$ surgery at postoperative months $1,3,6$, 12 , and 24 , and finally, at the most recent follow-up visit. 
Main outcome measures. The primary outcomes were the clinical characteristics associated with secondary $\mathrm{MH}$, which included the indications for initial vitrectomy, features on optical coherence tomography, and adjuvant surgical techniques during the initial surgery. Patients were also grouped according to a 1-line or 3-lines visual gain and a 3-lines visual loss for comparison. Furthermore, in cases of eyes operated on for MH closure, we grouped the patients according to whether a single operation or multiple reoperations for $\mathrm{MH}$ closure were required. Thus, secondary outcomes included the change in BCVA at 24 months post-operation for MH closure, clinical factors associated with the need for multiple operations for $\mathrm{MH}$ closure and prognostic factors associated with the visual outcomes.

Statistical analysis. We performed statistical analyses using the IBM SPSS version 22.0 software (IBM Corp., Armonk, NY, USA). Kolmogorov-Smirnov tests were used to analyse the distribution of samples. The independent $t$ and chi-square tests were used to compare the groups. Logistic regression analyses were performed to assess the impacts of various patient and treatment factors on the outcomes. All data are presented as mean \pm standard deviation. $P$ values $<0.05$ were considered statistically significant.

\section{Data availability}

The datasets generated during and/or analysed during the current study are available from the corresponding author on reasonable request.

Received: 1 March 2019; Accepted: 27 October 2019;

Published online: 20 December 2019

\section{References}

1. Moshfeghi, A. A. et al. Management of macular holes that develop after retinal detachment repair. Am J Ophthalmol 136, 895-899, https://doi.org/10.1016/S0002-9394(03)00572-5 (2003).

2. Lee, S. H. et al. Secondary macular hole formation after vitrectomy. Retina 30, 1072-1077, https://doi.org/10.1097/ IAE.0b013e3181cd4819 (2010).

3. Schlenker, M. B., Lam, W. C., Devenyi, R. G. \& Kertes, P. J. Understanding macular holes that develop after repair of retinal detachment. Can J Ophthalmol 47, 435-441, https://doi.org/10.1016/j.jcjo.2012.05.001 (2012).

4. Gass, J. D. Reappraisal of biomicroscopic classification of stages of development of a macular hole. Am J Ophthalmol 119, 752-759 (1995).

5. Smiddy, W. E. \& Flynn, H. W. Jr. Pathogenesis of macular holes and therapeutic implications. Am J Ophthalmol 137, 525-537, https://doi.org/10.1016/j.ajo.2003.12.011 (2004).

6. Brooks, H. L. Jr. Macular hole surgery with and without internal limiting membrane peeling. Ophthalmology 107, 1939-1948 (2000).

7. Kim, S. H., Kim, H. K., Yang, J. Y., Lee, S. C. \& Kim, S. S. Visual Recovery after Macular Hole Surgery and Related Prognostic Factors. Korean J Ophthalmol 32, 140-146 (2018).

8. Fabian, I. D. et al. Macular hole after vitrectomy for primary rhegmatogenous retinal detachment. Retina 32, 511-519, https://doi. org/10.1097/IAE.0b013e31821f5d81 (2012).

9. Sawaguchi, S. et al. Macular Hole Formation Identified with Intraoperative Oct during Vitrectomy for Vitreomacular Traction Syndrome. Retin Cases Brief Rep 11, 380-382, https://doi.org/10.1097/ICB.0000000000000377 (2017).

10. Gao, X., Ikuno, Y., Fujimoto, S. \& Nishida, K. Risk factors for development of full-thickness macular holes after pars plana vitrectomy for myopic foveoschisis. Am J Ophthalmol 155, 1021-1027 e1021, https://doi.org/10.1016/j.ajo.2013.01.023 (2013).

11. Medina, C. A. et al. Macular Hole after Pars Plana Vitrectomy for Rhegmatogenous Retinal Detachment. Retina 37, 1065-1072, https://doi.org/10.1097/IAE.0000000000001351 (2017).

12. Kumagai, K., Ogino, N., Furukawa, M., Larson, E. \& Uemura, A. Surgical outcomes for patients who develop macular holes after pars plana vitrectomy. Am J Ophthalmol 145, 1077-1080, https://doi.org/10.1016/j.ajo.2008.01.030 (2008).

13. Gaudric, A. et al. Macular hole formation: new data provided by optical coherence tomography. Arch Ophthalmol 117, 744-751 (1999).

14. Khurana, R. N. et al. The Association of Epiretinal Membrane with Macular Hole Formation after Rhegmatogenous Retinal Detachment Repair. Retina 37, 1073-1078, https://doi.org/10.1097/IAE.0000000000001307 (2017).

15. Cheng, L. et al. Effects of preoperative and postoperative epiretinal membranes on macular hole closure and visual restoration. Ophthalmology 109, 1514-1520 (2002).

16. Paques, M. et al. Late reopening of successfully treated macular holes. Br J Ophthalmol 81, 658-662 (1997).

17. Nam, K. Y. \& Kim, J. Y. Effect of internal limiting membrane peeling on the development of epiretinal membrane after pars plana vitrectomy for primary rhegmatogenous retinal detachment. Retina 35, 880-885, https://doi.org/10.1097/IAE.0000000000000421 (2015).

18. Garcia-Arumi, J. et al. Macular holes after rhegmatogenous retinal detachment repair: surgical management and functional outcome. Retina 31, 1777-1782, https://doi.org/10.1097/IAE.0b013e31820a69c3 (2011).

19. Gaucher, D. et al. Long-term follow-up of high myopic foveoschisis: natural course and surgical outcome. Am J Ophthalmol 143, 455-462, https://doi.org/10.1016/j.ajo.2006.10.053 (2007).

\section{Author contributions}

Conception and design: H.G. Kang \& M. Kim. Data collection: H.G. Kang, J.Y. Han, S.H. Byeon, S.S. Kim, H.J. Koh, S.C. Lee, \& M. Kim. Analysis and interpretation: H.G. Kang, J.Y. Han, E.Y. Choi, \& M. Kim. Overall responsibility: H.G. Kang, J.Y. Han, E.Y. Choi, S.H. Byeon, S.S. Kim, H.J. Koh, S.C. Lee \& M. Kim.

\section{Competing interests}

The authors declare no competing interests.

\section{Additional information}

Correspondence and requests for materials should be addressed to M.K.

Reprints and permissions information is available at www.nature.com/reprints. 
Publisher's note Springer Nature remains neutral with regard to jurisdictional claims in published maps and institutional affiliations.

(c) (i) Open Access This article is licensed under a Creative Commons Attribution 4.0 International License, which permits use, sharing, adaptation, distribution and reproduction in any medium or format, as long as you give appropriate credit to the original author(s) and the source, provide a link to the Creative Commons license, and indicate if changes were made. The images or other third party material in this article are included in the article's Creative Commons license, unless indicated otherwise in a credit line to the material. If material is not included in the article's Creative Commons license and your intended use is not permitted by statutory regulation or exceeds the permitted use, you will need to obtain permission directly from the copyright holder. To view a copy of this license, visit http://creativecommons.org/licenses/by/4.0/.

(c) The Author(s) 2019 